\title{
Compondo percursos gestuais: a dança na formação inicial de professores de Educação Física
}

\section{Composing sign routes: dance in the initial training of teachers of Physical Education}

\author{
Rita de Cássia Fernandes Miranda* \\ Mônica Caldas Ehrenberg**
}

\begin{abstract}
RESUMO
Esta pesquisa teve como objetivo refletir sobre as experiências da docência no ensino superior, vivenciadas na intervenção com os conhecimentos da dança em uma disciplina do curso de licenciatura em Educação Física de uma universidade pública do estado de Minas Gerais, no período de 2013 a 2015. Participaram da pesquisa quatro turmas de quarto período, totalizando 173 alunos de ambos os sexos. O planejamento inicial da intervenção ocorreu em julho de 2013, sendo reestruturado nos semestres subsequentes. Adotamos o enfoque da pesquisa-ação em articulação com as contribuições dos estudos culturais. Constatamos que o estudo e a experimentação dos elementos coreológicos foram fundamentais à pesquisa corporal, subsidiando a prática, a criação, a reflexão e a apreciação, contribuindo para a educação das sensibilidades e diluição das dicotomias entre forma e conteúdo.
\end{abstract}

Palavras-chave: Dança. Educação Física. Educação superior.

\begin{abstract}
This research aimed to reflect about the experiences of teaching in higher education, lived through the intervention of the knowledge of dance in a discipline of the teaching course in Physical Education of a public University

DOI: $10.1590 / 0104-4060.50458$

* Universidade Federal de Juiz de Fora. Governador Valadares, Minas Gerais, Brasil. Campus Avançado de Governador Valadares. Av. Doutor Raimundo Rezende, nº 330. Centro. CEP: $35012-$ 140. E-mail: rifernandes36@gmail.com

** Universidade de São Paulo. São Paulo, São Paulo, Brasil. Av. da Universidade, no 308. Butantã. CEP: 05508-040. E-mail: monica.ce@usp.br
\end{abstract}


of the State of Minas Gerais, from 2013 to 2015. Four classes of fourth quarter participated in the survey, totaling 173 students of both sexes. The initial planning of the intervention occurred in July 2013, and was restructured in subsequent semesters. We have adopted the approach of action research in conjunction with the contributions of cultural studies. We have found that the study and experimentation of coreológicos elements were fundamental to the body research, subsidizing practice, creation, reflection and appreciation, contributing to the education of sensitivities and the dilution of dichotomies between form and content.

Keywords: Dancing. Physical Education. Higher education.

\section{Passos iniciais}

A formação inicial de professores tem sido uma temática recorrente nos debates acadêmicos na contemporaneidade. No contexto da educação física, esse movimento parece ter se intensificado nos últimos anos, especialmente após a aprovação do Plano Nacional de Educação (Lei nº 13.005/14), bem como das novas Diretrizes Curriculares Nacionais para a formação inicial e continuada dos profissionais do magistério da educação básica, tendo por base o Parecer CNE/ CP 02/2015. Por certo, sabemos que a formação inicial tem como uma de suas principais responsabilidades a aproximação coerente e crítica com a realidade dos campos de intervenção profissional dos futuros professores, utilizando-se das práticas pedagógicas proporcionadas no decorrer do curso (NASCIMENTO et al., 2009) e do estágio curricular obrigatório como ferramenta para minimizar os problemas enfrentados na inserção no ambiente escolar (SHIGUNOV; FARIAS; NASCIMENTO, 2002).

É notório que as múltiplas demandas do cenário educacional atual sinalizam a necessidade de um novo perfil docente, indicando a centralidade desse campo para a consecução de determinadas intencionalidades formativas. Apontamos ainda como necessária a reflexão sobre o rol de conhecimentos postos em ação nos currículos de formação inicial, os quais, além de posicionarem os sujeitos na realidade social, acabam veiculando diferentes sentidos e significados sobre o próprio currículo, fruto das relações históricas e de poder presentes no confronto da heterogeneidade dos grupos que compõem a sociedade. Por conseguinte, em muitas situações, os próprios docentes não se reconhecem como autores do currículo, entendido com base em Silva (2007), na condição de território de luta pela hegemonia cultural e espaço de conflitos pela validação dos significados. 
Ao considerarmos o objeto do presente estudo, qual seja, refletir sobre a dança como conhecimento a ser tratado pela educação física, sentimo-nos instigadas ao aprofundamento do debate acerca de sua sistematização na formação inicial de professores para a educação básica, confrontando os problemas reais da prática, no cotidiano escolar, com as recentes teorizações da área.

Estudos anteriores (SBORQUIA, 2002; PORPINO; TIBÚRCIO, 2007; LARA; VIEIRA, 2010; BRASILEIRO, 2008, 2009, 2012; EHRENBERG, $2008,2014)$ já têm refletido e apresentado propostas sobre o ensino da dança e da intervenção pedagógica na formação inicial em educação física, chamando a atenção para a necessidade de articulação desses conhecimentos ao projeto político-pedagógico (PPP) dos cursos. Para Brasileiro (2012, p. 201), "uma formação que tem a dimensão estética como meta diferencia-se por ampliar as possibilidades de apropriação do conhecimento".

Entretanto, quando se analisa o conjunto da produção acadêmica que discute os currículos de formação inicial em educação física, notamos a necessidade de esforço investigativo que coloque em suspeição paradigmas formativos vigentes pautados na racionalidade técnica e na reprodução acrítica de práticas pedagógicas, apresentando proposições para a construção de uma nova epistemologia para a formação de professores como sugere Barbosa-Rinaldi (2008). Por certo, entendemos que problematizar o contexto da formação inicial em educação física torna-se um convite, mas também uma oportunidade de potencializar as responsabilidades pedagógicas deste campo do conhecimento, tomando a educação superior na condição de lócus investigativo e a universidade como contexto privilegiado de produção e socialização de conhecimentos.

$\mathrm{Na}$ mesma direção, ressaltamos a urgência de que seja considerada a complexidade dos âmbitos de atuação profissional da educação física, além da promoção de estratégias que possam aproximar tais contextos às instituições formadoras. Modificar o quadro atual que fragmenta os conhecimentos, separando teoria e prática a partir de visões lineares, coloca-se como horizonte na sistematização dos conhecimentos da dança na formação inicial de professores, apesar dos desdobramentos relevantes dos processos de reestruturação curricular de grande parte dos cursos nos últimos anos, a fim de atender aos ordenamentos legais e às novas demandas educacionais, sociais e políticas.

Corroborando os dizeres de Tardif (2000, p. 21) para o qual “[...] já é tempo de os professores universitários da educação começarem também a realizar pesquisas e reflexões críticas sobre suas próprias práticas de ensino", problematizamos os princípios das práticas pedagógicas construídas na formação inicial de professores de educação física, em especial no trato com a dança. Defendemos o enfrentamento dos desafios de tematizar tais conhecimentos, vislumbrando intervenções pedagógicas que ressaltem a multiplicidade de 
sentidos e significados que esta prática corporal pode assumir para os diferentes sujeitos que a experienciam, buscando superar a instrumentalização dos conhecimentos da dança.

Nessa perspectiva, a presente pesquisa intenciona refletir sobre as experiências da docência no ensino superior, vividas em um curso de licenciatura em educação física de uma universidade pública do estado de Minas Gerais, no período de 2013 a 2015, fundamentada na intervenção com os conhecimentos da dança na disciplina de "Estudos da Linguagem Corporal". Ressaltamos que na matriz curricular do curso, o componente curricular em questão estava alocado no quarto período e tinha como objetivo conhecer, vivenciar e refletir sobre o universo da linguagem corporal, enfatizando a expressão corporal nos diversos contextos histórico-culturais, além dos estilos de dança e seus significados ao longo do tempo.

A partir dessas considerações iniciais, com o intuito de documentar e analisar a prática pedagógica desenvolvida, aprender com as experiências e poder disseminar os resultados, assumimos a perspectiva da pesquisa-ação, buscando "tomar consciência dos princípios que nos conduzem em nosso trabalho" (TRIPP, 2005, p. 449), além de justificar melhor as ações pedagógicas e os fundamentos das decisões metodológicas, opção que será detalhada a seguir.

\section{Percurso metodológico}

Por ser um tipo de pesquisa colaborativa e compromissada com a formação, identificamos a pertinência da pesquisa-ação para o fortalecimento da prática cotidiana da docência no ensino superior. Nessa direção, Thiollent (2009) sinaliza que, a partir dos pressupostos metodológicos da pesquisa-ação, os educadores estariam em melhores condições de produzir conhecimentos implicados; ou seja, mais efetivos e com maior aplicabilidade ao nível pedagógico, inclusive abrindo possibilidades de generalizações parciais, algo que, obviamente, nos motivou ao encaminhamento da pesquisa. O mesmo autor nos chama a atenção que a pesquisa-ação não se basta apenas pela participação ou mesmo pela intervenção frente ao problema a ser resolvido, mas demanda a produção de conhecimentos, evidentemente, "[...] sendo cotejada com resultados de pesquisadas anteriores, e estruturada em conhecimentos" (THIOLLENT, 2009, p. 24).

Ainda de acordo com Thiollent (2009), uma das especificidades da pesquisa-ação consiste em intercambiar dois tipos de objetivos: a) objetivo prático: visando contribuir para o melhor equacionamento do problema da pesquisa, a 
partir de soluções e propostas de ações que embasem os atores em sua atividade transformadora da situação; b) objetivo de conhecimento: prima pela obtenção de informações que seriam de difícil acesso por meio de outros procedimentos, favorecendo conhecimentos de situações específicas.

Alguns aspectos citados por Bracht (2002) e Betti (2009), com base no autor supracitado acerca das especificidades da pesquisa-ação, nos ajudam a compreendê-la de forma mais acurada. Dentre esses fatores destacamos: as significativas interações entre pesquisador/a e sujeitos da pesquisa; o estabelecimento das prioridades frente ao(s) problema(s) pesquisado(s) e às soluções propostas; o esclarecimento ou resolução dos problemas da situação identificada; o acompanhamento das decisões e das ações dos atores envolvidos, além da ampliação dos conhecimentos do/a pesquisador/a.

Com base no referencial teórico dos estudos culturais, concebemos a cultura como território de luta em que são travadas disputas pela significação, ou seja, qualquer processo de transmissão cultural não se faz de modo tranquilo, pelo contrário, envolve o embate entre diferentes grupos sociais (HALL, 2003). Como ferramenta de análise no campo educacional, os estudos culturais têm contribuído para a desnaturalização de saberes e práticas, explicitando que determinadas arquiteturas curriculares gestam projetos identitários específicos, e o conhecimento como sistema de significação está vinculado às relações de poder.

Portanto, o contexto das aulas é concebido como lócus privilegiado para a socialização, ressignificação e ampliação da linguagem corporal, sendo o gesto elemento constituinte " $[\ldots]$ das múltiplas possibilidades por meio das quais os seres humanos se comunicam e expressam intencionalidades e modos de ser, pensar e agir, característicos do grupo cultural com os quais estabelecem vínculos e relações" (NEIRA; NUNES, 2009, p. 16).

Importa ressaltar que participaram da pesquisa quatro turmas de quarto semestre de um curso de licenciatura em educação física de uma universidade pública situada no estado de Minas Gerais, entre 2013 a 2015, totalizando 173 alunos de ambos os sexos. O planejamento inicial ocorreu em julho de 2013, processo este que se repetiu predominantemente antes do início de cada semestre.

\section{Do cotidiano da pesquisa em ação: os bastidores}

Ao assumirmos as aulas da disciplina em questão, visto que não foi possível participar da elaboração do PPP do curso, a proposta inicial foi buscarmos compreender a própria nomenclatura, ementa e objetivos da disciplina em articulação 
ao PPP do curso. Nesse processo, foram identificadas algumas incoerências as quais reproduzem uma situação já denunciada por Marques (2001). A autora aponta que outras denominações, como "expressão corporal" e "educação do movimento", têm sido empregadas neste componente curricular, escamoteando os reais objetivos de um trabalho com a dança, a fim de que, dentre outros fatores, um número maior de alunos/as tenha acesso a ela, especialmente, os do gênero masculino.

De saída, podemos afirmar que como já havíamos ministrado disciplina semelhante em outras instituições de ensino, certos aspectos pareciam se perpetuar, principalmente àqueles relacionados à passividade e ao distanciamento de alguns alunos/as nas atividades voltadas para os processos de criação e apreciação nas aulas. Cabe aqui ressaltarmos que tal aspecto configura o problema concreto sobre o qual se debruçou esta pesquisa-ação. Amparadas em Marques (2000, p. 43), apontamos que "o desafio que se coloca hoje é o de estabelecer conexões significativas entre a apreciação e a participação que se encontram na problematização do olhar, do sentir, do fazer e do viver em uma sociedade tecnológica." Na nossa visão, este quadro é acentuado, especialmente quando nos referimos à dança no contexto da formação inicial em educação física, afinal recebemos muitos alunos/as que tiveram experiências negligenciadas com a dança na educação básica.

Do mesmo modo, compreendermos aquele novo cenário, no qual as tecnologias da comunicação teimavam em aparecer na mão, no bolso ou, por solicitação, dentro da mochila dos/as alunos/as, parecia primordial no intuito de mapear suas influências na própria estruturação das práticas pedagógicas. "Como encontrar espaço para a consistência, a insistência e a permanência em meio às fragilidades das relações atuais, banhadas por ferramentas virtuais sociais como o messenger e o facebook, entre outros?" (MUNDIM, 2012, p. 106).

Importa considerarmos outros fatores como o espaço-tempo destinado às aulas, às concepções dos discentes e demais docentes sobre a relevância da disciplina na formação inicial, a "intensidade" da relação professor-aluno, os materiais disponíveis, o caráter público da instituição, entre outros que apesar de não serem determinantes para as práticas pedagógicas, certamente interferem, pois constituem esse "entorno" que deve ser responsabilizado (REZER; FENSTERSEIFER, 2008).

Somente para exemplificar o anteriormente exposto, caso se tenha um ambiente muito amplo, incompatível com a capacidade do aparelho de som disponível ou um espaço pequeno demais em relação à quantidade de alunos na turma, podemos acabar dificultando as possibilidades gestuais ou cerceando o aproveitamento de novos diálogos, de sobreposições do gesto e da música. Contudo, não descartamos que tais restrições são interessantes para o processo 
e produto coreográfico, mas que essa opção seja definida a priori com objetivos específicos e não por falta de opção.

Para organizar o trabalho pedagógico, o planejamento foi arquitetado a partir de unidades didáticas, as quais, na visão de Damis (2006), favorecem a perspectiva global e contextualizada do aprendizado, incentivando o protagonismo dos sujeitos e valorizando seus conhecimentos prévios. Assim, "por meio dessa técnica, os professores programam o trabalho e decidem sobre os objetivos pretendidos, as atividades para enriquecer as experiências, os estudos dos alunos e a avaliação que acompanha todo o processo". (DAMIS, 2006, p. 127). Aliás, esperamos que todo planejamento educacional tenha coerência, clareza de suas especificidades e fundamentação como aspectos a serem buscados em qualquer nível de ensino, realidade esta que infelizmente tem sido negligenciada na educação física por diferentes motivos, relegando o planejamento à função meramente burocrática, dificultando inclusive a luta pela legitimidade do componente.

Desse modo, foram estruturadas quatro unidades didáticas para o desenvolvimento da disciplina, a saber: na primeira unidade, foi explorada a contextualização histórica dos sentidos e significados da dança ao longo do tempo, seus diferentes contextos de prática e objetivos, enfatizando possibilidades e objetivos da dança na escola; na segunda unidade, foram tematizados os elementos coreológicos, além do registro, avaliação e apreciação de coreografias. Já na terceira unidade didática, estabelecemos aproximações aos saberes circenses e suas possibilidades expressivas. Por último, enfatizamos a prática do maculelê e da dança-afro, buscando fomentar discussões sobre as interfaces da educação física com as questões étnico-raciais. Finalizamos o processo com a elaboração de composições coreográficas em grupo.

Na sequência, centraremos nossas discussões na segunda unidade didática, na qual tratamos dos aspectos coreológicos como mote para a experimentação e análise dos elementos constitutivos da dança, tendo as referências metodológicas do trabalho desenvolvido por Porpino e Tibúrcio (2007) em contexto similar ao que se analisa.

\section{As aulas, o palco: sujeitos em cena}

A preocupação inicial deste processo foi com o que se denominou de "sensibilização corpórea", sugerindo o contato com o próprio corpo e com o corpo do outro, por meio de toques, além da atenção às articulações. Buscamos 
trazer os participantes para um espaço-tempo peculiar de criação e fruição, despertando gestos pouco enfatizados no cotidiano, valorizando a "escuta gestual" sensível no diálogo com seus pares, tal qual nos sugere Mundim (2012, p. 110), "[...] a escuta é essencial em quatro dimensões complementares: a escuta de si, a escuta do outro em cena, a escuta do entorno, a escuta do público". Afinal, a intenção era de superar o aprendizado da dança como simples decodificação e imitação de passos, numa abordagem espontaneísta de sequências ou técnicas específicas carentes de sentidos e significados.

Vale ressaltar que a dança tratada no ambiente educacional não compreende o público apenas como pessoas externas ao grupo de trabalho (familiares, expectadores, plateia em geral) e, portanto, ao considerarmos a citação anterior da autora enfatizamos a relevância do olhar como fundamental aspecto no processo de ensino e aprendizagem da dança. Não colocamos a performance ou a apresentação de final de curso como mais importante, mas olhar os colegas e experimentar não apenas o corpo em ação, mas também experimentar a apreciação pode contribuir para a formação de espectadores. Isso também faz parte dos papéis das manifestações artísticas na escola.

A dança, assim como as demais artes, não existe para ser traduzida em palavras, mas sim sentida, vivenciada, contemplada. Sua função não é a de comunicar significados, mas a de exprimir sentidos. Esses sentidos são experimentados tanto dançando, como também contemplando. Claro está que a viabilização do ensino da dança na formação inicial através dos aspectos coreológicos nos processos de improvisação e composição coreográfica representa uma dentre tantas outras possibilidades de tornar o ensino reflexivo e crítico com base nas situações vividas, de fomentar a pesquisa gestual e a apreciação das produções coletivas, enfim, de intensificar os canais de comunicação entre docente e discentes, aceitando as limitações do grupo como nos lembram Porpino e Tibúrcio (2007).

Com ênfase na perspectiva da educação estética (SARAIVA, 2009), entendemos que a dança em seus pressupostos, saberes e práticas pode buscar no gesto formas dialógicas de compreender o corpo na condição de território da cultura com enfoque nos processos de criação, fruição e apreciação, superando perspectivas instrumentais e reducionistas da dança. Há aqui um esforço em orientar e estimular os discentes em formação a reconhecerem a dança como uma forma de expressão. Pautados por uma formação tecnicista, comumente os professores de educação física têm mais facilidade em perceber as habilidades motoras e as capacidades físicas na dança do que seu potencial comunicativo e expressivo. Essa é uma maneira reducionista de compreender a dança como conhecimento a ser tratado também pela educação física. As habilidades e as capacidades devem ser consideradas, mas não podem ser objetivos únicos da 
proposição de atividades pedagógicas, pois desse modo o professor passa a ser "um educador com muito pouco de formador, com muito mais de treinador, de transferidor de saberes, de exercitador de saberes" (FREIRE, 1996, p. 162, grifo do autor).

Desse modo, é preocupante o fato de que muitos/as professores/as formadores/as, conforme nos chama a atenção Gariglio (2010, p. 24), negligenciam "a centralidade da dimensão interativa na relação com os alunos, seja individualmente, seja coletivamente", demonstrando certo descompasso frente às especificidades dos campos de atuação e da natureza dos conhecimentos da área.

Por isso, no decorrer das ações didáticas, buscamos estimular a contextualização dos múltiplos sentidos e significados que a dança tem assumido nos diferentes contextos da sociedade, além dos efeitos que as diferentes abordagens de ensino exercem na constituição identitária de crianças e jovens frente aos apelos da cultura midiática. Entretanto, sem desqualificar qualquer estilo de dança, mas provocando os/as alunos/as a perceberem como estão assentadas as relações de poder, questões de gênero e visões de mundo no interior desses grupos sociais.

De fato, na tentativa de aprofundar as discussões sobre as questões de gênero e identidade observadas e manifestadas nas aulas, optamos por tomá-las como objeto de estudos. Foi percebido que os discursos dos discentes nas aulas estavam carregados de binarismos e estereótipos, inclusive com verbalizações de preconceitos frente aos quais coube indagar sobre o papel da educação física escolar no que se refere à constatação e à perpetuação dessas representações.

As estratégias utilizadas a partir de análise de textos e matérias jornalísticas, além das discussões sobre o filme "Billy Elliot", representaram uma tentativa de problematização e desconstrução das representações que os discentes tinham sobre as questões de gênero e identidade no que tange à dança. Para os estudos culturais importa desnaturalizar o fato de que os discursos veiculados produzem efeitos diversos, os quais provocam a imposição de identidades de grupos culturais em detrimento de outros, como se houvesse um só modo de ser homem, mulher, professor, aluno e aluna. Defendemos que a tematização da dança no âmbito da formação inicial bem como na escola não pode prescindir do questionamento dos marcadores sociais nela presentes, como etnia, gênero, classe social, níveis de habilidade entre outros, pois "o currículo é, entre outras coisas, um artefato de gênero: um artefato que, ao mesmo tempo, corporifica e produz relações de gênero." (SILVA, 2007, p. 97)

Outras estratégias metodológicas foram empregadas durante as aulas e algumas delas estão presentes inclusive na proposta de Ehrenberg (2014), tais como: jogos cênicos; apreciação e análise crítica de vídeos; leituras e discussões de textos; improvisação a partir de sons corporais; mímicas; exercícios técnicos 
de dança; utilização de materiais alternativos (sombrinhas, lenços, garrafas de água, cadeiras); emprego de estímulos sonoros, visuais e literários; pesquisa gestual com temas do cotidiano; vivência de situações-problemas com respostas verbais ou gestuais; práticas de consciência corporal.

Identificamos que a adoção desses procedimentos durante as aulas, por favorecerem um contexto mais democrático, participativo e lúdico, tem contribuído para que os discentes assumam o protagonismo no processo de aprendizado; ou seja, se percebam como autores/as de suas próprias práticas, favorecendo o enfrentamento do problema nuclear desta pesquisa-ação. Assertivamente lembram Bracht e Caparroz (2007) que o papel do/a professor/a de educação física não pode se restringir a "aplicação" de teorias na prática, mas de produção de conhecimentos, de estudo e de pesquisa. Além disso, confirmam que o exercício da docência na contemporaneidade demanda dos processos formativos a apropriação e (re)construção dos conhecimentos necessários para o desenvolvimento de intervenções pedagógicas com qualidade.

Obviamente o cotidiano das aulas não foi isento de tensões, ambiguidades e contradições nos/dos processos vividos. Ora, aqueles participantes que de alguma forma não se identificavam com a disciplina, ou se mostravam resistentes à aproximação dos colegas, seja por timidez, seja por medo de se exporem, entre outros fatores, transitavam pelas bordas, numa posição mais de espectadores do que propriamente de participantes. Enfim, acordos tácitos ou não, negociações curriculares, provocadas "por meio de resistências não confessadas" (SACRISTAN; PEREZ GOMEZ, 2000, p. 19), foram realizadas a fim de que interações mais significativas acontecessem.

Neste contexto, nem sempre as aulas ocorreram da forma como planejado, sendo necessário reorientar as ações, incluir outros materiais, flexibilizar as propostas a partir das relações estabelecidas. As proposições de Tardif (2000) de que os conhecimentos profissionais são situados e, por isso, (re)construídos pelos atores em função das especificidades dos contextos de trabalho, nos conduziram a novas situações, sugerindo que o exercício da docência requer a tomada de decisão na ação, num processo de contínua reflexão e, portanto, de formação permanente.

\section{Mediando possibilidades coreográficas}

A partir dos temas escolhidos coletivamente mediados pela docente, foram organizadas as possibilidades de composição coreográfica. Frisamos que a proposta não era que apenas um/a aluno/a ficasse responsável pela criação, mas que, 
partindo da pesquisa teórica e gestual inicial feita por cada grupo, o processo fosse constituído coletivamente. Entretanto, foi inevitável que em alguns grupos a liderança tenha sido assumida por participantes que já tinham experiências anteriores com a dança ou teatro, por exemplo. Mesmo assim, foi reforçada a necessidade de colaboração e adequação dos gestos escolhidos, respeitando as possibilidades expressivas de todo o grupo, além da exploração das habilidades individuais.

Observamos ao longo das aulas que embora a diversidade de gestualidades se fizesse presente, era perceptível a inexperiência de vários/as alunos/as com a dança, seus códigos e suas possibilidades estéticas e expressivas. Concomitantemente, constatamos que as experiências anteriores vividas com a dança por alguns facilitaram a transmutação dos sentidos gestuais presentes nas ações cotidianas para as especificidades do gesto dançante, a fim de que pudessem receber um tratamento poético, algo que também foi percebido no trabalho de Porpino e Tibúrcio (2007).

Outra questão relevante durante o processo foi a busca por objetos e materiais para compor o lugar cênico capazes de articular o tema escolhido. Alguns foram localizados no próprio ambiente das aulas, enquanto outros objetos foram trazidos pelos discentes. Algumas possibilidades se materializaram ainda em espaços diversos da instituição com o aproveitamento de folhas secas, pinhas, terra, entre outros elementos que assumiram a função de objetos estéticos.

Nesse ínterim, matizado pela composição do trabalho final da disciplina, cada um dos grupos se concentrava em determinado local (ginásio ou salas multiuso) da instituição e a docente responsável fazia o trânsito entre estes espaços mediando o processo. No que se refere à escolha do repertório musical, ainda que tivéssemos estudado os elementos básicos da música, os critérios de escolha frente aos apelos midiáticos, a música como linguagem artística, entretenimento, entre outras questões; pelo menos metade dos grupos utilizou músicas mais conhecidas ou tocadas na mídia, levando-nos a discutir posteriormente quanto à adequação das escolhas ao contexto da educação física escolar visto que se tratava de um curso de formação de professores.

Buscando oferecer subsídios para que tivessem melhores condições de avaliar a qualidade daquilo que estavam criando, foi apresentado um roteiro com questões ligadas aos aspectos coreológicos trabalhados em aula, por exemplo, quanto à ampla utilização do espaço no que se refere aos níveis, planos, direções, progressões, formas, tensões espaciais; as possibilidades de utilização das intencionalidades nas/ das formações coreográficas; os diferentes tipos de organização do trabalho coletivo; a interação entre os participantes e a expressividade; a percepção rítmica; a criatividade em novas descobertas gestuais.

Pudemos identificar também que diferentes estratégias de composição foram exploradas pelos grupos, ou seja, os sujeitos criaram formas muito próprias 
de organização das sequências e frases gestuais, numa busca por nexos, numa lógica narrativa naquilo que criavam. Alguns grupos partiram da escuta atenta e repetida da música para a posterior associação com os gestos, já outros grupos iam criando as cenas ou ideias-chave, tentando, posteriormente, inserirem na música. Tais possibilidades em certos momentos causaram conflitos no coletivo a serem mediados pela docente.

Contudo, defendemos que o trabalho coreográfico possui muitas possibilidades de estruturação, não devendo se pautar na simples reprodução e memorização de uma sequência de gestos e passos codificados, mas num rico momento coletivo de troca criativa (COSTA, 2004), de diálogo para a escritura de um texto poético-gestual que potencialize experiências estéticas qualitativas a fim de modificar a própria realidade. Certamente, outros olhares para o corpo e o gesto que desafiam a desconstruir sentidos e significados naturalizados no trato da dança na formação inicial em educação física, e esperamos também no contexto escolar.

Vale salientar que durante o período no qual acompanhamos os grupos, percebemos as dificuldades encontradas nas relações interpessoais, no exercício de lidar com as diferenças, as frustrações e os receios a fim de sentirem-se efetivamente parte do grupo. Na busca pelos consensos, cada ideia ou proposta pode ou não ser aceita, gerando novos diálogos, outras proposições, elucidando como a dança intenciona ser um espaço de convívio político, artístico e afetivo. (MUNDIM, 2012).

Ao final do processo de apreciação das composições coreográficas, os grupos foram convidados a comentarem sobre as experiências vividas, e a forma como percebiam os resultados apresentados, fazendo, inclusive, uma autoavaliação, algo fundamental para o processo da pesquisa-ação. Para muitos, aquela oportunidade de se apresentarem coletivamente com figurino, maquiagem, som e luz, especialmente após se tornarem adultos, havia sido a primeira para a maioria e o produto final havia superado as expectativas. Os discentes relataram ainda que apesar dos conflitos surgidos durante o processo de criação, a busca pelo entrosamento e a dedicação da maioria para o alcance dos objetivos traçados facilitou a finalização da proposta.

\section{Considerações finais}

Na busca pela superação da denúncia de que parte do discurso pedagógico, produzido pela educação física nas últimas décadas, não é efetivado através de 
práticas educacionais concretas. Analisamos os fazeres docentes, consubstanciados nas práticas pedagógicas com a dança, a fim de contribuir com os avanços das investigações no que se refere aos conhecimentos necessários à atuação profissional na educação física.

Replicando sentidos e potencializando conhecimentos em dança, destacamos que o estudo e a experimentação dos elementos coreológicos foram fundamentais à pesquisa corporal, subsidiando a prática, a criação, a reflexão e a apreciação. Do mesmo modo, entendemos que a proposta contribuiu para a educação das sensibilidades, bem como para a diluição de dicotomias entre forma e conteúdo. A dança com ênfase em sua dimensão estética permitiu refletir sobre os princípios didático-metodológicos para o ensino dessa manifestação corporal na escola.

Foi possível constatarmos na pesquisa algumas perspectivas para o ensino da dança nos cursos de licenciatura em educação física e que, a nosso ver, indicam a relevância deste estudo para a área, quais sejam: a possibilidade de análise do gesto cotidiano para a criação em dança; a centralidade do contexto vivido e das situações experienciadas como mote para o ensino e aprendizado; a composição coreográfica pautada pelo trabalho cooperativo; o diálogo respeitoso entre os atores do processo, especialmente nas tomadas de decisão; a definição de critérios claros para compor e avaliar; o reconhecimento dos limites e possibilidades da dança como conhecimento a ser tratado pela educação física. Além disso, a pesquisa-ação permitiu o estabelecimento de uma relação de confiança entre as partes envolvidas, sendo instrumento relevante não somente para o desenvolvimento profissional do professorado, mas também um caminho fértil para a implantação de reformas educacionais.

Entretanto, algumas dificuldades identificadas nas experiências vividas, além da falta de experiências prévias dos discentes com a dança, indicam as limitações da pesquisa e sugerem a necessidade de revisão de elementos presentes nos códigos da dança, bem como a problematização do repertório musical escolhido pelos grupos. As estratégias empregadas no estudo deste tema se mostraram de certa forma ineficazes para a mudança dos critérios de escolha adotados e dos estereótipos.

Portanto, entendemos que talvez seja impossível fazer, contextualizar e apreciar dança, sem falar de uma memória criadora, poética e de formas de pensamento mais flexíveis que abram mão daquele espaço que nos é confortável. Tais inquietações sugerem que o ensino das linguagens artísticas não pode mais se pautar em "receitas prontas" que impossibilitam os sujeitos de dizerem o que tem a dizer, mas, em contrapartida, vemos a urgência de propiciar experiências estéticas qualitativas. 
Enfim, com vistas ao enfrentamento dos problemas advindos da prática docente com os conhecimentos da dança, especialmente quanto à postura passiva de alguns discentes, como apontamos no início do texto, consideramos que trazer para o "centro do palco-quadra" a capacidade crítico-reflexiva, o protagonismo decisório e, principalmente, histórias de vida na tessitura desses conhecimentos, matiza o esforço pedagógico para constituir uma cultura acadêmica para o ensino da dança na formação inicial de professores de educação física.

\section{REFERÊNCIAS}

BARBOSA-RINALDI, I. P. Formação inicial em Educação Física: uma nova epistemologia da prática docente. Movimento, Porto Alegre, v. 14, n. 3, p. 185-207, set./dez. 2008.

BETTI, M. Educação Física escolar: ensino e pesquisa-ação. Ijuí: Editora Unijuí, 2009.

BRACHT, V. et al. A prática pedagógica em educação física: a mudança a partir da pesquisa-ação. Revista Brasileira de Ciências do Esporte, Florianópolis, v. 23, n. 2, p. 9-29, jul. 2002.

BRACHT, V.; CAPARROZ, F. E. O tempo e o lugar de uma didática da educação física. Revista Brasileira de Ciências do Esporte, v. 28, n. 2, p. 21-37, jan. 2007.

BRASIL. Conselho Nacional de Educação. Resolução CNE/CP n. 02/2015, de $1^{\circ}$ de julho de 2015. Define as Diretrizes Curriculares Nacionais para a formação inicial em nível superior (cursos de licenciatura, cursos de formação pedagógica para graduados e cursos de segunda licenciatura) e para a formação continuada. Disponível em: $<$ http://portal.mec. gov.br/index.php?option=com_docman\&view=download\&alias=17719-res-cne-cp-00203072015\&category_slug=julho-2015-pdf\&Itemid=30192 >. Acesso em: 20 fev. 2017.

BRASIL. Lei $n^{\circ} 13.005$, de 25 de junho de 2014. Aprova o Plano Nacional de Educação - PNE e dá outras providências. Disponível em: <http://www2.camara.leg.br/legin/fed/ lei/2014/lei-13005-25-junho-2014-778970-publicacaooriginal-144468-pl.html>. Acesso em: 10 mar. 2017.

BRASILEIRO, L. T. O ensino da dança na Educação Física: formação e intervenção pedagógica em discussão. Motriz, v. 14, n. 4, p. 519-528, out./dez. 2008.

BRASILEIRO, L. T. Dança-Educação Física: (in)tensas relações. Tese (Doutorado em Educação) - Faculdade de Educação, Universidade Estadual de Campinas, Campinas, SP. 2009.

BRASILEIRO, L. T. Dança: sentido estético em discussão. Movimento, Porto Alegre, v. 18, n. 01, p. 189-203, jan./mar. 2012. 
COSTA, E. M. O corpo e seus textos: o estético e o político na dança. 2004. Tese (Doutorado em Educação Física) - Faculdade de Educação Física, Universidade Estadual de Campinas, Campinas, SP. 2004.

DAMIS, O. T. Unidade didática: uma técnica para a organização do ensino e da aprendizagem. In: VEIGA, I. P. A. Técnicas de ensino: novos tempos, novas configurações. Campinas: Papirus, 2006. p. 105-135.

EHRENBERG, M. C. Os currículos de licenciatura em educação física: a dança em questão. 2008. Tese (Doutorado em Educação Física) - Faculdade de Educação Física, Universidade Estadual de Campinas, Campinas, SP. 2008.

EHRENBERG, M. C. A dança nos cursos de licenciatura em educação física: diagnósticos e possibilidades. In: EHRENBERG, M. C.; FERNANDES, R. de C.; BRATIFISCHE, S. A. (Orgs.). Dança e educação física: diálogos possíveis. 1. ed. Várzea Paulista, SP: Fontoura, 2014. p. 25-47.

FREIRE, P. Pedagogia da autonomia: saberes necessários à prática educativa. 12. ed. São Paulo: Paz e Terra, 1996.

GARIGLIO, J. A. O papel da formação inicial no processo de constituição da identidade profissional de professores de educação física. Revista Brasileira de Ciências do Esporte, Florianópolis, v. 32, n. 2-4, p. 11-28, dez. 2010.

HALL, S. Da diáspora. Identidades e mediações culturais. Belo Horizonte: UFMG, Brasília: Representações da UNESCO no Brasil, 2003.

LARA, L. M.; VIEIRA, A. P. Em foco: o corpo que dança: experiências docentes e intersubjetividades desafiadas. In: LARA, L. M. (Org.). Abordagens socioculturais em educação física. Maringá: Eduem, 2010. p. 20-45.

MARQUES, I. Apreciação e interatividade: casos que dançam. Revista Comunicação \& Educação, São Paulo, v. 19, p. 39-45, set./dez. 2000.

MUNDIM, A. C. A composição em tempo real: um lugar de convívio artístico, político e afetivo. In: MUNDIM, A. C. (Org.). Dramaturgia do corpo-espaço e territorialidade: uma experiência de pesquisa em dança contemporânea. Uberlândia: Composer, 2012. p. 13-27.

NASCIMENTO, J. V. et al. Formação acadêmica e intervenção pedagógica nos esportes. Motriz, Revista da Educação Física, Rio Claro, v. 15, n. 2, p. 358-66, 2009.

NEIRA, M. G.; NUNES, M. L. F. (orgs.). Praticando estudos culturais na educação física. São Caetano do Sul, SP: Yendis Editora, 2009.

PORPINO, K. de O.; TIBURCIO, L. K. de O. M. Cenas urbanas e cenas da dança: compondo novos repertórios pedagógicos no contexto do ensino superior. Revista Brasileira de Ciências do Esporte, Campinas, v. 28, n. 2, p. 141-154, jan. 2007.

REZER, R.; FENSTERSEIFER, P. E. Docência em Educação Física: reflexões acerca de sua complexidade. Pensar a Prática, v. 11, n. 3, p. 319-329, set./dez. 2008. 
SARAIVA, M. do C. Elementos para uma concepção do ensino de dança na escola: a perspectiva da educação estética. Revista Brasileira de Ciências do Esporte, Campinas, v. 30, n. 3, p. 157-171, maio 2009.

SBORQUIA, S. P. A dança no contexto da educação fisisica: os (des)encontros entre a formação e a atuação profissional. 2002. Dissertação (Mestrado em Educação Física) Faculdade de Educação Física, Universidade Estadual de Campinas, Campinas. 2002.

SHIGUNOV, V.; FARIAS, G. O.; NASCIMENTO, J. V. O percurso profissional dos professores de Educação Física nas escolas. In: SHIGUNOV, V.; SHIGUNOV NETO, A. (Orgs.). Educação Física: conhecimento teórico x prática pedagógica. Porto Alegre: Mediação, 2002. p. 19-53.

SILVA, T. T. Documentos de identidade: uma introdução às teorias do currículo. Belo Horizonte: Autêntica, 2007.

TARDIF, M. Saberes profissionais dos professores e conhecimentos universitários. Revista Brasileira de Educação, ANPED, n. 13, p. 5-23, 2000.

THIOLLENT, M. Metodologia da pesquisa-ação. 17. ed. São Paulo: Cortez, 2009.

TRIPP, D. Pesquisa-ação: uma introdução metodológica. Revista Educação e Pesquisa, São Paulo, v. 31, n. 3, p. 443-466, set./dez. 2005.

Texto recebido em 02 de fevereiro de 2017. Texto aprovado em 16 de fevereiro de 2017. 